\title{
HISTORIA DE LA MEDICINA
}

\section{Repertorio de Antaño \\ TRATAMIENTO DE LAS OTITIS MEDIAS}

Tomado de la revista "Repertorio de Medicina y Cirugía" volumen VII No. 1 octubre de 1915. Por el Doctor Luis Maria Rivas M. De Bogotá

Conocida como es la rebeldía de las otitis medias supuradas a todo tratamiento y lo peligrosas que son ya como causa de sordera incurable por ankilosis de los huesecillos ya por determinar, más o menos tarde, abscesos cerebrales o complicaciones meningeas, he creido oportuno hacer conocer la observación siguiente que demuestra la necesidad del examen auricular sistemático en los niños atacados de infecciones nasolaríngicas y bronquias, así como la eficacia del tratamiento de Pech por éter sulfúrico.

El niño J.A.R., de dos años de edad, fue atacado de bronquitis aguda generalizada a los gruesos y medianos bronquios de ambos pulmones con temperatura de $39^{\circ}$ y 39,5 .

Lo traté con revulsión, benzoato de soda, expectorantes y baños calientes. Después de quince dias de tratamiento la temperatura bajó a $36^{\circ}$ y décimos, los signos estetoscópicos desaparecieron, el apetito volvió y todo correspondió a una convalescencia franca.

Tres dias más tarde la temperatura subió a $40^{\circ}$; se presentaron vómitos frecuentes y el niño lloraba quejándose incesantemente y llevaba la mano a la cabeza sin precisar el sitio del dolor.

No encontrando signo alguno que me revelara la causa de estos síntomas, pensé en una complicación meníngea, aunque nada no lo demostrara claramente, y en consecuencia llamé en consulta a un distinguido profesor, quien después de examinarlo detenidamente diagnosticó una bronconeumonía en focos pequeños que evolucionaba paulatinamente.
De acuerdo con sus indicaciones volvi a tratarlo con baños calientes, piramidón, benzoato de soda, etc., sin obtener resultados, pero dos dias después, al visitarlo, lo encontré sin fiebre, contento, jugando y pidiendo su tetero que tomaba con avidez; el oído derecho había superado y al examen, después de un lavado con agua hervida, se veía una perforación del tímpano.

En el aparto respiratorio no percibí signo alguno.

En consecuencia instituí un tratamiento con baños de fenosaltil, y benzoato de soda al interior.

Pocos días después se volvían a presentar la fiebre y los vómitos y el llanto, que desaparecieron a la supuración del oido izquierdo.

El tratamiento descrito más arriba fue sostenido por un mes sin obtener más resultado que disminuír la supuración y suprimir los síntomas.

Ya había prevenido a la madre para una enfermedad de varios meses, cuando de casualidad vi en el Monitor Terapéutico que Pech había curado en seis semanas una otorrea consecutiva a coqueluche y que databa de veinte años; por medio de éter puro. Quise ensayar el tratamiento y en consecuencia prescribi que después del lavado antiséptico se llenara el oído de éter sulfúrico tapando con algodón aséptico, esto una vez por la noche. Ocho días después el niño estaba curado persistiendo la curación hace más de tres meses.

Como se ve, el resultado confirma las observaciones de Pech y es sencillísimo. 


\section{HISTORIA DE LA MEDICINA}

\section{COMENTARIO}

Luis Fernando Rincón MD*

En el artículo tratamiento de la otitis media del Dr. Luís María Rivas, vemos cómo la aparición y evolución de la enfermedad no ha cambiado, pero si percibimos una disminución en cuanto a las complicaciones, posiblemente porque en la actualidad tenemos más medios de diagnóstico y terapéuticos, que hacen que el diagnóstico se haga temprano y reciba el tratamiento requerido. También existe la posibilidad que en la actualidad el paciente consulte más temprano y así se instaure un tratamiento ambulatorio y eficaz.

Al Igual que el doctor Rivas, observamos que los pacientes con otitis media que presentan perforación timpánica tienen regresión de su sintomatologia más rápido, por descompresión del oído medio al expulsar el contendido purulento de este.
En cuanto al tratamiento sí existe una controversia, ya que en la actualidad no se usa éter sulfúrico para la resolución de las otitis medias. Se emplean antibióticos orales, tópicos o endovenosos según el caso; se realizan limpiezas periódicas bajo microscopio para secar el oúdo y en caso crónico sin perforación timpánica, se pensaría en colocar tubos de ventilación. Sin embargo, también utilizamos medidas generales y en ocasiones usamos lavados de oído con ácido acético para erradicar la infección. Esto se realiza en caso que el paciente no pueda adquirir los medicamentos o se requiera combinar dichos tratamientos.

* Otólogo, servicio de otorrinolaringología, Hospital de San José. Instructor Asistente Fundación Universitaria de Ciencias de la Salud. 